\title{
ANALISIS TEKNO-EKONOMI PENERAPAN TEKNOLOGI BIOREFINERY PADA PABRIK KELAPA SAWIT
}

\section{TECHNO-ECONOMIC ANALYSIS ON IMPLEMENTATION OF BIOREFINERY TECHNOLOGY IN PALM OIL MILL}

\author{
Edi Hilmawana, Ati Widiati ${ }^{\mathrm{a}}$, , Ayu Lidie Febriyania, $^{\mathrm{a}}$, Ratna Etie Puspita Dewi ${ }^{\mathrm{a}}$ \\ a Pusat Pengkajian Industri Proses dan Energi (PPIPE) BPPT, \\ Gd. 720 Kawasan Puspiptek Tangsel, tel. +62-21-75791384 ext. 6111 \\ e-mail : edi.hilmawan@bppt.go.id, ati.widiati@bppt.go.id, ayu.lydi@bppt.go.id, ratna.etie@bppt.go.id.
}

\begin{abstract}
Abstrak
Penerapan teknologi biorefinery pada Pabrik Kelapa Sawit (PKS) melalui pemanfaatan kembali dan daur ulang limbah atau produk samping, dapat meningkatkan efisiensi proses serta nilai tambah dari diversifikasi produk. Dalam studi ini dilakukan kajian tekno-ekonomi peluang penerapan teknologi biorefinery pada PKS dengan kapasitas terpasang 45 ton-TBS per jam, yang berlokasi di Riau. Opsi teknologi biorefinery yang dikaji ada 4 skenario, yaitu: (a) Skenario 1: PLT Biogas + Pabrik Pellet, (b) Skenario 2: PLT Biogas + Pabrik Kompos, (c) Skenario 3: Biogas Cofiring dan (d) Skenario 4: Biogas Cofiring + Activated Carbon. Hasil analisa teknoekonomi menunjukkan bahwa keempat opsi teknologi biorefinery di atas, layak untuk diterapkan di PKS. Instalasi PLTBg dapat menghasilkan listrik yang lebih murah daripada PLN, sehingga teknologi pellet maupun kompos memiliki kelayakan finansial yang cukup menarik. Skenario biogas cofiring sangat tergantung pada harga cangkang yang digantikan sebagai bahan bakar. Proyek secara tekno-ekonomi menjadi tidak layak, ketika harga cangkang di bawah Rp 500/kg. Untuk PKS yang sudah terpasang sistem PLTBg, direkomendasikan untuk mengaplikasikan pabrik pellet ataupun kompos memanfaatkan listrik dari PLTBg. Sedangkan yang belum terpasang sistem PLTBg, dapat dipertimbangkan untuk memanfaatkan biogas sebagai bahan bakar boiler, sehingga dapat menghemat cangkang yang memiliki nilai jual tinggi di pasar.
\end{abstract}

Kata kunci : Zerowaste; Biorefinery; Tekno-ekonomi; Pabrik Kelapa Sawit

\begin{abstract}
Application of biorefinery technology to the Palm Oil Mill (POM) could improve process efficiency and added value of diversified product, by reusing or recycling wastes and/or by-products. In this study, a technoeconomic study of the opportunities for applying biorefinery technology to POM with a capacity of 45 tons-TBS per hour, located in Riau. There are 4 options of biorefinery technology examined in this study; those are: (a) Scenario 1: Biogas PP + Pellet Plant, (b) Scenario 2: Biogas PP + Compost Plant, (c) Scenario 3: Biogas Cofiring and (d) Scenario 4: Biogas Cofiring + Activated Carbon. Techno-economic analysis results show that all of the biorefinery technology options are feasible to be implemented in POM. Biogas Power Plant (BFPP) installations can produce electricity cheaper than PLN so that the technology of pellets and compost has quite attractive financial feasibility. The biogas cofiring scenario is highly dependent on the price of shells replaced as fuel. The project is technically not feasible, when shell prices down under Rp 500/kg. In POM having a BFPP system installed, it is recommended to apply the pellet mill or compost using electricity from the BFPP, while those that have not installed the BFPP system can utilize
\end{abstract}


biogas as fuel for boiler, and saving shells that have a higher value in the market.

Key Words : Zerowaste; Biorefinery; Techno-economic analysis; Palm Oil Mill

Diterima (received): 05 Februari 2020, Direvisi (revised): 18 Maret 2020,

Disetujui (accepted): 24 Maret 2020

\section{PENDAHULUAN}

Indonesia merupakan negara produsen minyak sawit terbesar di dunia dengan produksi mencapai 51,83 Juta ton pada tahun 2019, yang terdiri dari 47,18 juta ton Crude Palm Oil (CPO) dan 4,65 juta ton Palm Kernel Oil (PKO) ${ }^{1}$. Angka ini lebih besar sekitar $9,3 \%$ dari produksi tahun 2018 , yang sebesar 47,39 juta ton.

Dengan teknologi pengolahan kelapa sawit yang ada saat ini, hanya sekitar $20 \%$ yang dapat diambil sebagai produk $\mathrm{CPO}^{2)}$. Sisanya terbuang dalam bentuk limbah, baik limbah padat maupun limbah cair. Untuk meningkatkan efisiensi proses dan nilai tambah produk, perlu dipertimbangkan pemanfaatan kembali limbah maupun produk samping melalui daur ulang ataupun diversifikasi produk yang memiliki nilai tambah lebih tinggi, melalui pemanfaatan teknologi biorefinery (kilang hayati).

Biorefinery adalah fasilitas yang mengintegrasikan proses konversi biomassa dan peralatan untuk menghasilkan bahan bakar, daya, panas, dan bahan kimia bernilai tambah dari biomassa ${ }^{3)}$. Konsep biorefinery dapat dianalogikan dengan kilang minyak bumi saat ini, yang menghasilkan banyak bahan bakar dan produk dari minyak bumi. Bedanya kilang minyak bumi menggunakan bahan baku fosil yang tidak terbarukan, sedangkan biorefinery berbahan baku biomassa yang bersifat terbarukan. Konsep biorefinery merupakan salah satu terobosan teknologi yang mengintegrasikan proses pengolahan biomassa untuk menghasilkan bioenergi dan biomaterial. Hal ini membawa paradigma baru industri pengolahan yang mengarah kepada industri proses yang lebih ramah lingkungan dan berkelanjutan (sustainable) $)^{4}$.

Transformasi pabrik kelapa sawit dari sekedar pabrik pengolahan kelapa sawit menjadi pabrik biorefinery, merupakan tema yang menarik perhatian dalam 10 tahun terakhir ${ }^{5,6,27}$. Di samping karena potensi kelapa sawit yang sangat besar, juga dikarenakan meningkatnya tuntutan daya saing industri serta tuntutan untuk menyediakan material pengganti dari yang bersumber dari minyak bumi menjadi bersumber biomassa yang lebih ramah lingkungan. Kelapa sawit dengan segala turunannya merupakan salah satu sumber biomassa yang sangat potensial untuk menggantikan minyak bumi sebagai bahan baku produksi material-material tertentu. Buah kelapa sawit dapat dianggap sebagai salah satu bahan baku yang berpotensi untuk biorefinery karena mengandung $67-84 \%$ karbohidrat dan $15-33 \%$ lignin dalam tandan buah kosong. Bahan baku ini dapat dimanfaatkan untuk memproduksi bioetanol generasi kedua, bahan kimia, panas dan daya ${ }^{7}$.

Dalam studi ini dibahas kelayakan teknoekonomi peluang penerapan teknologi biorefinery pada pabrik Kelapa Sawit, dengan kapasitas 45 ton-Tandan Buah Sawit (TBS), yang berlokasi di Propinsi Riau. Kajian kelayakan tekno-ekonomi dilakukan terhadap beberapa pilihan teknologi yang diseleksi berdasarkan Tingkat Kesiapterapan Teknologi (Technology Readiness Level, TRL) ${ }^{8)}$ serta mempertimbangkan kelayakan penerapannya secara teknis.

\section{BAHAN DAN METODE}

Pabrik Kelapa Sawit (PKS) yang menjadi obyek studi berlokasi di Kabupaten Kampar, Provinsi Riau dengan kapasitas olah terpasang sebesar 45 ton-TBS per jam. Proses pengolahan kelapa sawit pada PKS ini sebagaimana layaknya pabrik kelapa sawit yang lain (Gambar 1), meliputi:

1) Proses Penimbangan dan Penyortiran Buah Sawit

2) Proses Perebusan (Sterilizing Process),

3) Proses Penebahan (Thresser Process),

4) Proses Pengempaan (Pressing Process).

5) Proses Pemurnian Minyak (Clarification Process), serta

6) Proses Pengolahan Biji (Kernel Station).

PKS ini juga dilengkapi dengan sistem utilitas, yang meliputi antara lain: 1) Sistem Pengolahan Air, 2) Sistem Uap, dan 3) Sistem Kelistrikan. PKS yang dikaji saat ini sudah memasang Pembangkit Listrik Tenagas Biogas (PLTBg) dengan kapasitas terapasang 1,4 MW memanfaatkan biogas hasil pengolahan limbah cair dari pabrik (Palm Oil Mill Effluent, POME). Karena untuk kebutuhan produksi sudah dapat dipenuhi dari Pembangkit Listrik Tenaga Uap (PLTU) Biomassa berbahan bakar limbah sabut (fiber) dan cangkang, kelebihan listrik produksi 
PLTBg ini digunakan untuk memasok listrik tidak jauh dari lokasi PKS. untuk Pabrik Pengolahan Kernel yang terletak

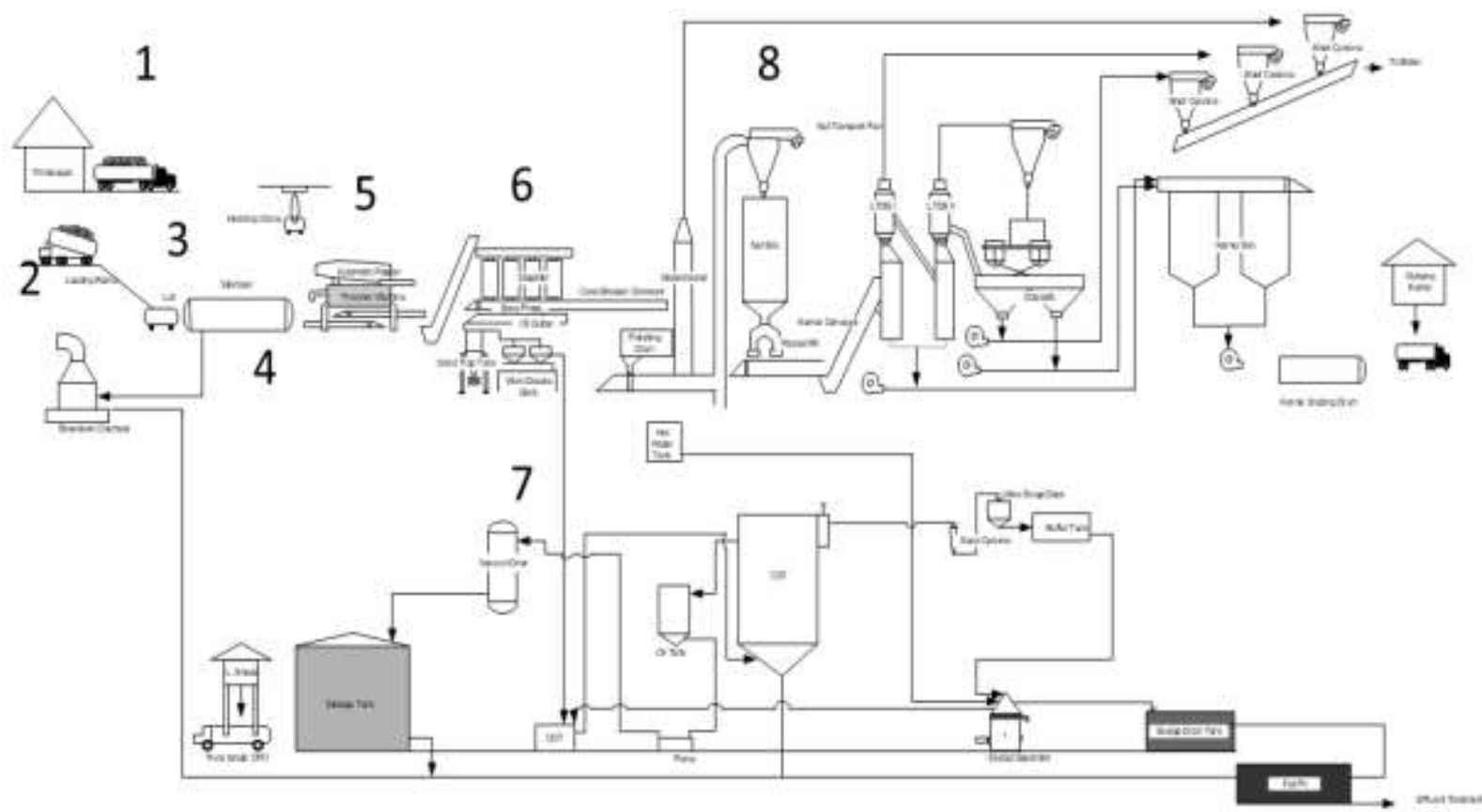

Gambar 1.

Diagram Alur Proses di PKS

(1) Proses Penimbangan, (2) Proses Penyortiran, (3) Proses Loading, (4) Proses Perebusan, (5) Proses Penebahan, (6) Proses Pengempaan, (7) Proses Pemurnian Minyak, dan (8) Proses Pengolahan Biji.

Tabel 1.

Skala Pengukuran $T R L^{8)}$

\begin{tabular}{|c|c|}
\hline Level & Keterangan \\
\hline TRL 1 - & basic principles observed \\
\hline TRL $2-$ & technology concept formulated \\
\hline TRL $3-$ & experimental proof of concept \\
\hline TRL $4-$ & technology validated in laboratory \\
\hline TRL $5-$ & $\begin{array}{l}\text { technology validated in relevant environment (industrially relevant environment in the case of key } \\
\text { enabling technologies) }\end{array}$ \\
\hline TRL $6-$ & $\begin{array}{l}\text { technology demonstrated in relevant environment (industrially relevant environment in the case of key } \\
\text { enabling technologies) }\end{array}$ \\
\hline TRL $7-$ & system prototype demonstration in operational environment \\
\hline TRL 8 - & system complete and qualified \\
\hline TRL $9-$ & $\begin{array}{l}\text { actual system proven in operational environment (competitive manufacturing in the case of key } \\
\text { enabling technologies or in space) }\end{array}$ \\
\hline
\end{tabular}

Pemilihan opsi teknologi biorefinery dilakukan menggunakan evaluasi tingkat kesiapterapan teknologi (technology readiness level, TRL) $)^{8}$. Proses penilaian TRL dilakukan berdasarkan hasil review teknologi menurut literatur, publikasi ilmiah dan juga survei lapangan. TRL adalah pengukuran tingkat kematangan teknologi sampai dengan siap untuk digunakan secara luas, yang diinisasi oleh $N A S A^{8)}$. Pada perjalanannya metode ini diadopsi dan disempurnakan oleh European Association of Research and Technology Organizations (EARTO) sebagai salah satu tool untuk perancanaan dalam manajemen inovasi (innovation management) ${ }^{9,10)}$. Skala dalam 
pengukuran TRL mulai dari level 1-9 dapat dilihat pada Tabel 1.

Opsi teknologi yang dipilih adalah opsi teknologi yang sudah memiiki nilai TRL $>6$. Kelayakan teknis dari tiap opsi teknologi dianalisis berdasarkan neraca massa dan neraca energi pabrik saat ini, kondisi peralatan terpasang, utilitasi peralatan serta data-data operasional pabrik selama tahun 2018-2019. Analisa tekno-ekonomi dilakukan dengan menghitung kebutuhan biaya investasi dan biaya operasional pabrik, serta tambahan penerimaan dari diversifikasi produk sebagai hasil dari penerapan teknologi biorefinery. Parameter-parameter kelayakan teknoekonomi seperti IRR, PBP, ROI dan BCR digunakan untuk menilai kelayakan masingmasing opsi teknologi biorefinery.

\section{HASIL DAN PEMBAHASAN}

\section{Hasil Penilaian TRL Teknologi Biorefinery}

Sekalipun terdapat banyak opsi teknologi biorefinery yang dapat diterapkan pada PKS, namun tidak semua teknologi sudah layak untuk diterapkan secara komersial pada PKS. Hasil review teknologi berdasarkan penilaian TRL dirangkum pada Tabel 2. Beberapa referensi yang digunakan dalam melakukan penilaian TRL ditampilkan pula dalam Tabel 2.

Tabel 2.

Rangkuman Nilai TRL Teknologi Biorefinery

\begin{tabular}{clcc}
\hline No & \multicolumn{1}{c}{ Teknologi } & TRL & Reff. \\
\hline 1 & $\begin{array}{l}\text { Electricity/ Cogeneration } \\
\text { Technology }\end{array}$ & 9 & 4), 5), 6) \\
2 & Biogas & 9 & 11), 12), 13), \\
& & & 29), 30) \\
3 & Compost & 9 & 14), 15), 16) \\
4 & Pellets and briquete & 8 & 6), 16) \\
5 & BioChar/ Activated & 6 & 7), 12), 28) \\
& Carbon & & \\
6 & Fast Pyrolysis & 5 & 17), 2,16) \\
7 & Bio-composite & 5 & 24), 25) \\
8 & Torrefaction & 5 & 6), 7) \\
9 & Bioethanol & 4 & 17, 20), 21). \\
10 & Pulp and Paper & 4 & 18) \\
11 & Bio-Plastic & 4 & 22) \\
12 & Hydrogen and Syngas & 4 & 5), 17), 18), \\
& & & 23) \\
13 & Food and Ruminants & 4 & 5) \\
14 & Chemicals & 3 & 5), 6), 26) \\
15 & Enzyme & 3 & 5) \\
16 & Phenol from Effluent & 3 & 13), 19) \\
\hline
\end{tabular}

Para peneliti banyak mengembangkan teknologi untuk mengolah limbah biomassa dari PKS sebagai bahan baku untuk produksi bahan kimia. Namun sayangnya kebanyakan teknologi yang dikembangkan masih pada tahap uji coba skala laboratorium dan belum siap untuk uji coba skala komersial $(T R L<6)$. Demikian juga teknologi untuk memproduksi bahan bakar pengganti bahan bakar fosil, seperti hidrogen maupun methanol masih pada TRL 4. Substitusi material komposit, maupun plastik dengan bio-komposit atau bio-plastik yang bersumber dari limbah PKS, juga masih pada skala pengujian di laboratorium (TRL 4-5) dan membutuhkan waktu untuk bisa diaplikasikan secara komersial. Sekalipun demikian ada beberapa teknologi yang sudah layak untuk diterapkan secara komersial, seperti produksi biogas dari limbah POME, cogeneration, pembuatan pellet dan kompos dari tandan kosong kelapa sawit (tankos). Untuk itu, pada kajian kali ini dipilih teknologi yang memiliki nilai $T R L>8$, untuk dikaji kelayakan penerapannya pada Pabrik Kelapa Sawit. Sebagai tambahan opsi dipertimbangkan juga produksi arang aktif dari cangkang sawit, yang nilai TRL-nya sudah lebih dari 6. Berdasarkan hasil tersebut, opsi teknologi biorefinery yang dikaji dalam penelitian ini ada 4 skenario, yaitu:

a) Skenario 1: PLT Biogas + Pabrik Pellet

b) Skenario 2: PLT Biogas + Pabrik Kompos

c) Skenario 3: Biogas Cofiring

d) Skenario 4: Biogas Cofiring + Activated Carbon

\section{Kinerja Pengolahan PKS}

PKS memiliki kapasitas terpasang 45 tonTBS per jam. Pada operasinya, rata-rata kapasitas pengolahan tahun 2018 berkisar 37,88 ton-TBS perjam. Kinerja pengolahan pabrik tahun 2017-2018 ditunjukkan pada Tabel 3.

Tabel 3

Rangkuman Kinerja PKS tahun 2017-2018

\begin{tabular}{lrr}
\hline \multicolumn{1}{c}{ Kinerja Pabrik } & \multicolumn{1}{c}{2017} & \multicolumn{1}{c}{2018} \\
\hline TBS Olah (ton) & 216.311 & 265.625 \\
Rendemen CPO (\%) & 22,43 & 23,36 \\
Rendemen Inti Sawit (\%) & 4,21 & 4,49 \\
\hline
\end{tabular}

Jika dibandingkan dengan tahun 2017, maka kinerja PKS meningkat. Jumlah TBS yang diolah meningkat $22,7 \%$, rendemen CPO meningkat $4,1 \%$ dan rendemen Inti Sawit juga meningkat $6,7 \%$.

Di sisi lain ratara-rata limbah biomasa yang dihasilkan untuk setiap $100 \mathrm{~kg}$ TBS olah selama tahun 2018 , sejumlah $21,5 \mathrm{~kg}$ tandan kosong (EFB), $11 \mathrm{~kg}$ sabut (fiber) dan 6,2 kg cangkang (shell). Selama ini sabut dan cangkang habis digunakan sebagai bahan 
bakar boiler, sedangkan tandan kosong dikembalikan ke kebun sebagai tambahan pupuk.

Limbah cair (POME) mencapai 67,69 kg per $100 \mathrm{~kg}$-TBS olah, dengan COD pada bulan April 2018 sebesar 35379 mg/l. Saat ini di PKS sudah terpasang PLT Biogas yang memanfaatkan limbah POME tersebut, dan menghasilkan listrik kurang lebih $800 \mathrm{~kW}$ yang digunakan sebagai sumber energi ke pabrik pengolahan inti sawit (PPKO) Tandun.

Berdasarkan data pengolahan pabrik selama tahun 2018-2019 dapat dihitung baseline neraca bahan dan energi dari PKS pada kapasitas 30 ton-TBS per jam, sebagaimana ditunjukkan pada Gambar 2. Dapat dilihat pada Gambar 2, bahwa dari 30
ton-TBS yang diolah di PKS, diperoleh CPO 7,27 ton dan Kernel 1,35 ton. Selain itu limbah yang dihasilkan berupa tandan kosong sebesar 6,45 ton. Limbah biomassa lainnya berupa sabut 3,45 ton dan cangkang 1,86 ton habis dibakar untuk boiler yang menghasilkan 8,1 ton uap untuk proses dan listrik $918 \mathrm{~kW}$. Limbah POME yang dihasilkan sejumlah 20 ton. Dengan kandungan COD sebesar 35379 mg/l, dari pengolahan POME tersebut diperoleh biogas setara $335 \mathrm{~m}^{3}$ yang jika dipakai untuk pembangkit listrik dapat menghasilkan $676 \mathrm{~kW}$ listrik. Kebutuhan listrik untuk proses hanya sebesar $412,5 \mathrm{~kW}$, maka diperoleh surplus listrik sebesar 1,187 MW yang dapat diekspor untuk kebutuhan di luar pabrik.

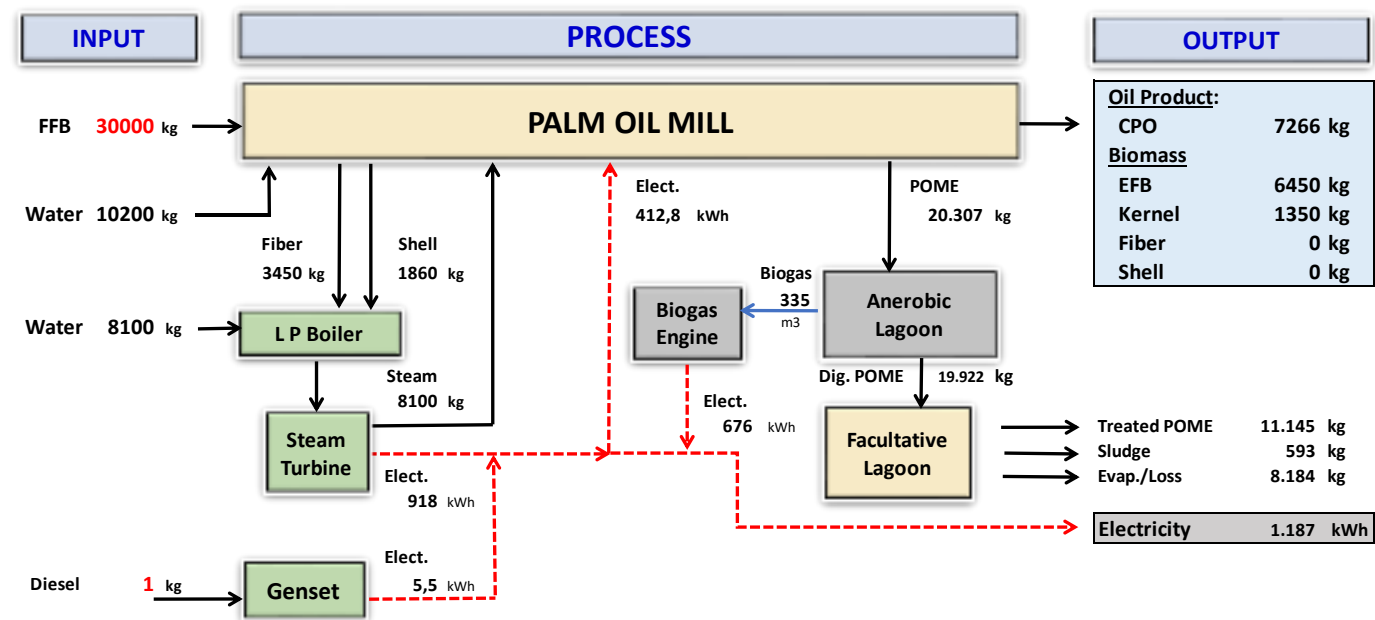

Gambar 2

Neraca bahan dan energi PKS pada kapasitas 30 ton-TBS per jam (baseline)

\section{Perhitungan Skenario Penerapan Teknologi Biorefinery}

Hasil perhitungan neraca massa dan energi pada kapasitas pengolahan 30 tonTBS per jam untuk masing-masing skenario, ditunjukkan pada Gambar 3-Gambar 6.

Total produksi selama setahun untuk masing-masing skenario dihitung dengan asumsi pabrik beroperasi selama $6000 \mathrm{jam} /$ tahun. Hasil perhitungan total produksi per tahun dirangkum pada Tabel 4

- Untuk skenario 1, dengan membangun pabrik pellet memanfaatkan limbah tankos, akan dihasilkan 13.300 ton pellet per tahun. Sebagian listrik akan digunakan untuk pengolahan pabrik pellet, sehingga listrik yang dihasilkan berkurang menjadi $658 \mathrm{MWh}$ dalam setahun.
- Pada skenario 2 dengan membangun pabrik kompos, maka limbah tankos yang ada dapat diolah untuk dihasilkan 15.480 ton kompos dan listrik yang kurang lebih sama dengan kondisi baseline.

- Pada skenario 3, diperoleh sisa cangkang dari efek penghematan bahan bakar boiler sejumlah 1.194 ton, namun limbah tankos yang tersisa sejumlah 38.700 ton dan listrik yang diekspor sebesar 3,064 MWh per tahun.

- Pada skenario 4, dengan membangun pabrik karbon aktif, maka cangkang yang dihemat pada skenario 3 dapat diolah untuk menghasilkan karbon aktif dihasilkan sebanyak 116 ton. 


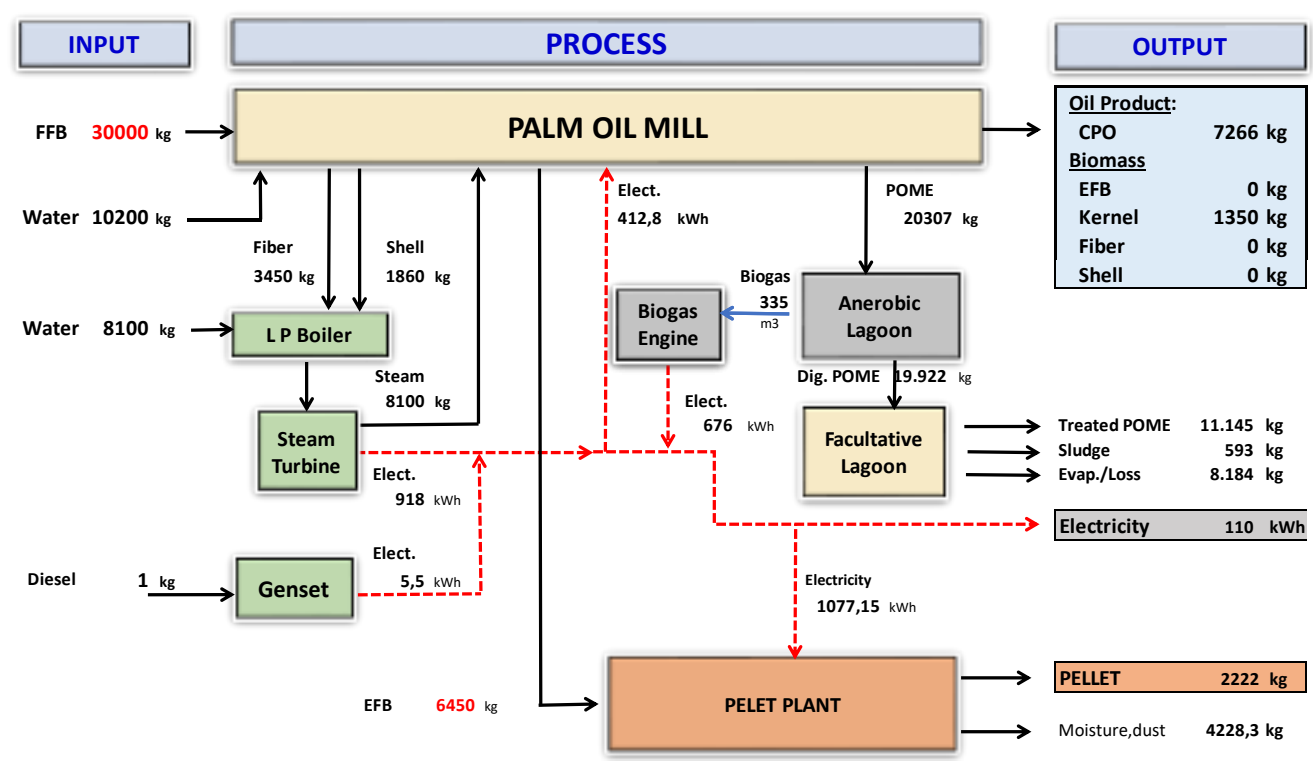

Gambar 3.

Neraca bahan dan energi PKS untuk skenario 1: PLT Biogas + Pellet Plant

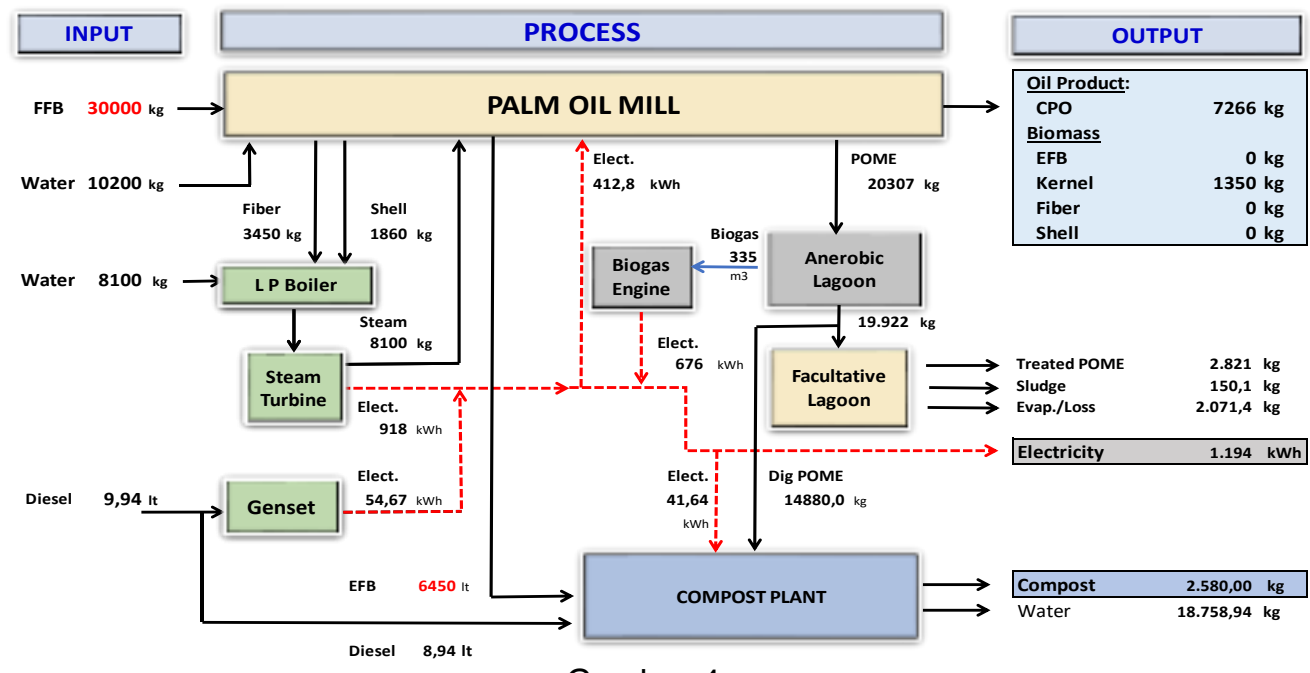

Gambar 4.

Neraca bahan dan energi PKS untuk skenario 2: PLT Biogas + Compost Plant

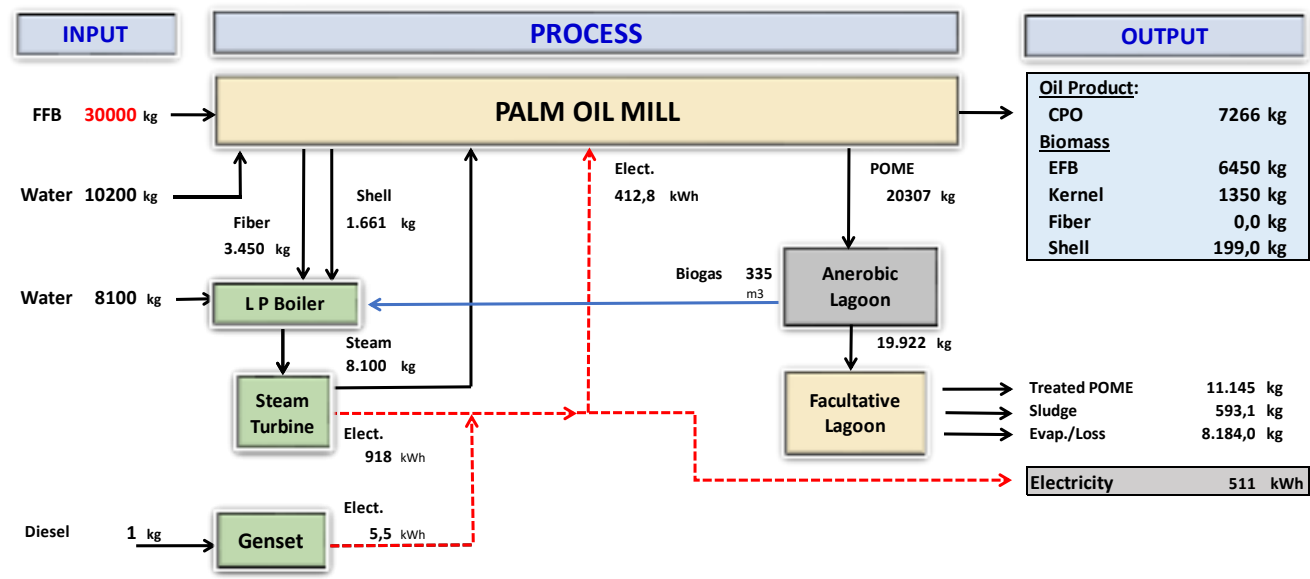

Gambar 5.

Neraca bahan dan energi PKS untuk skenario 3: Biogas Cofiring 


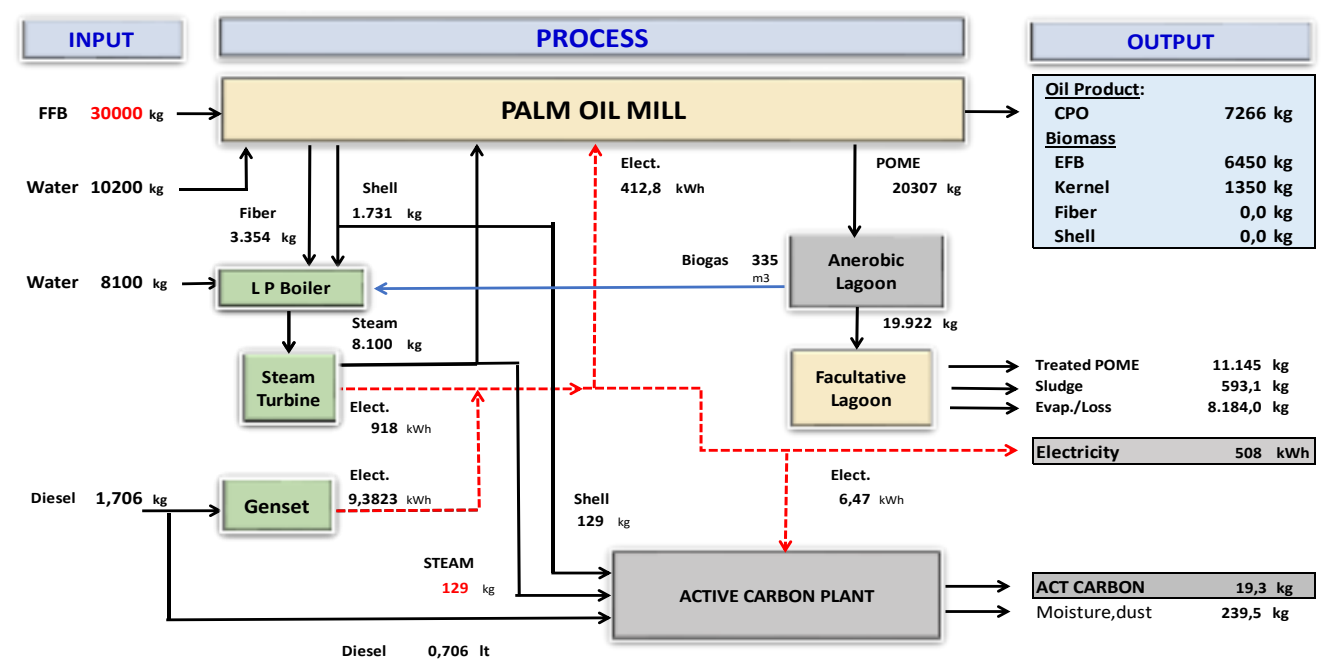

Gambar 6

Neraca bahan dan energi PKS untuk skenario 4: Biogas Cofiring + Activated Carbon Plant

Tabel 4

Perbandingan volume produksi pabrik untuk masing-masing skenario

\begin{tabular}{lrrrrr}
\hline \multicolumn{1}{c}{ Produk } & Baseline & Skenario 1 & Skenario 2 & Skenario 3 & Skenario 4 \\
\hline CPO (ton) & 43.596 & 43.596 & 43.596 & 43.596 & 43.596 \\
EFB (ton) & 38.700 & - & - & 38.700 & 38.700 \\
Kernel (ton) & 8.100 & 8.100 & 8.100 & 8.100 & 8.100 \\
Fiber (ton) & - & - & - & - & - \\
Shell (ton) & - & - & - & 1.194 & - \\
Electricity (MWh) & 7.121 & 658 & 7.166 & 3.064 & 3.049 \\
Compost (ton) & - & - & 15.480 & - & - \\
Pellet (ton) & - & 13.330 & - & - & - \\
Active Carbon (ton) & - & - & - & - & 116 \\
\hline **) asumsi cap factor $80 \%$ dan jam operasi 7500 jam/ tahun & &
\end{tabular}

\section{Pembahasan}

\section{Nilai Ekonomi Produk}

Produk yang dihasilkan dari masingmasing skenario memiliki nilai ekonomi yang berbeda-beda. Tabel 5 merangkum nilai ekonomi dari produk dan limbah yang dihasilkan dari masing-masing skenario dengan asumsi harga jual produk sebagaimana ditunjukkan pada Tabel 6 . Dari Tabel dapat dilihat bahwa skenario 2 yang paling tinggi nilai ekonominya. Pemasukan untuk skenario 2 diperoleh dari penjualan listrik dan penjualan kompos sebagai pupuk. Namun apabila dibandingkan per jenis komoditas yang bisa dijual, maka pellet memiliki nilai penjualan tertinggi dibandingkan dengan nilai penjualan komoditas yang lain.

\section{Biaya Investasi}

Biaya investasi yang diperlukan untuk pemasangan teknologi biorefinery dengan masing-masing skenario dapat dilihat pada Tabel 7. Nilai investasi untuk masing-masing skenario diperoleh dari literatur dan informasi yang diperoleh dari vendor. Dapat dilihat bahwa untuk skenario 1 diperlukan biaya investasi sebesar kurang lebih Rp. $14 \mathrm{M}$, sedangkan skenario 2 kurang lebih Rp. 12,3 M. Skenario 3 hanya membutuhkan biaya kurang lebih Rp. $1 \mathrm{M}$, karena saat ini PKS sudah memiliki fasilitas biogas, sehingga kebutuhan investasi hanya untuk mengalirkan gas dari kolam digester ke boiler terpasang (termasuk burner, blower dan sistem pemipaan). Bagi PKS yang belum memiliki fasilitas biogas, setidaknya diperlukan biaya investasi tambahan kurang lebih Rp. $13 \mathrm{M}$ untuk pembangunan sistem biogas yang meliputi sistem pre-treatment POME, biogas digester, sistem flaring dan sebagainya. Sedangkan biaya investasi untuk skenario 4 hanya sebesar Rp. $5 \mathrm{M}$, karena kapasitasnya yang kecil (kurang lebih $200 \mathrm{~kg} / \mathrm{h}$ ). 
Tabel 5.

Nilai Ekonomi produk dari masing-masing skenario

\begin{tabular}{lrrrrr}
\hline \multicolumn{1}{c}{ Produk } & \multicolumn{1}{c}{ Baseline } & Skenario 1 & Skenario 2 & Skenario 3 & Skenario 4 \\
\hline CPO & 325.792 .90 & 325.792 .90 & 325.792 .90 & 325.792 .90 & 325.792 .90 \\
EFB & 8 & 8 & 8 & 8 & 8 \\
Kernel & 1.935 .000 & - & - & 1.935 .000 & 1.935 .000 \\
Fiber & 43.245 .900 & 43.245 .900 & 43.245 .900 & 43.245 .900 & 43.245 .900 \\
Shell & - & - & - & - & - \\
Electricity & - & - & - & 596.974 & - \\
Compost & 10.017 .028 & 925.344 & 10.080 .585 & 4.310 .563 & 4.288 .707 \\
Pellet & - & - & 7.353 .000 & - & - \\
Activated Carbon & - & 10.637 .340 & - & - & - \\
\hline
\end{tabular}

Tabel 6.

Harga jual produk yang digunakan untuk Analisa Kelayakan Ekonomi

\begin{tabular}{ccccccccc}
\hline $\begin{array}{c}\mathrm{CPO} \\
(\mathrm{Rp} / \mathrm{kg})\end{array}$ & $\begin{array}{c}\mathrm{EFB} \\
(\mathrm{Rp} / \mathrm{kg})\end{array}$ & $\begin{array}{c}\text { Kernel } \\
(\mathrm{Rp} / \mathrm{kg})\end{array}$ & $\begin{array}{c}\text { Fiber } \\
(\mathrm{Rp} / \mathrm{kg})\end{array}$ & $\begin{array}{c}\text { Shell } \\
(\mathrm{Rp} / \mathrm{kg})\end{array}$ & $\begin{array}{c}\text { Electricit } \\
(\mathrm{Rp} / \mathrm{kWh})\end{array}$ & $\begin{array}{c}\text { Compost } \\
(\mathrm{Rp} / \mathrm{kg})\end{array}$ & $\begin{array}{c}\text { Pellet } \\
(\mathrm{RP} / \mathrm{kg})\end{array}$ & $\begin{array}{c}\text { Karbon } \\
\text { Aktif } \\
(\mathrm{Rp} / \mathrm{kg})\end{array}$ \\
\hline 7.473 & 50 & 5.339 & 50 & 500 & $1.406,75$ & 500 & 840 & 20.000 \\
\hline
\end{tabular}

Tabel 7.

Kebutuhan Investasi untuk masing-masing skenario

\begin{tabular}{ccccc}
\hline Skenario & Skenario 1 & Skenario 2 & Skenario 3 & Skenario 4 \\
\hline Investment cost (juta Rp) & 13.390 & 12.357 & 955 & 4.927 \\
\hline
\end{tabular}

Tabel 8.

Perbandingan komposisi biaya masing-masing skenario

\begin{tabular}{llrrrr}
\hline \multicolumn{1}{c}{ Costs } & \multicolumn{2}{c}{$\begin{array}{c}\text { Skenario 1 } \\
\text { BFPP + Pellet }\end{array}$} & $\begin{array}{c}\text { Skenario 2 } \\
\text { BFPP + Kompos }\end{array}$ & $\begin{array}{c}\text { Skenario 3 } \\
\text { Biogas-Cofiring }\end{array}$ & $\begin{array}{c}\text { Skenario 4 Biogas } \\
\text { Cofiring + Act Carbon }\end{array}$ \\
\hline Capital cost & (Rp/ton) & 103.379 & 86.692 & 79.738 & 4.281 .421 \\
Raw Material Cost & (Rp/ton) & 176.164 & 151.697 & 117.665 & 1.269 .510 \\
Fixed O\&M Cost & (Rp/ton) & 258,963 & 142.870 & 281.854 & 9.653 .110 \\
Variable O\&M Cost & (Rp/ton) & 331.911 & 95.797 & 57.934 & 2.856 .996 \\
\hline \multicolumn{1}{c}{ Total } & (Rp/ton) & 870.417 & 475.705 & 537.191 & 18.061 .036 \\
\hline
\end{tabular}

\section{Analisis Biaya}

Biaya produksi untuk masing-masing skenario dapat dipecah menjadi biaya modal, biaya bahan baku, dan biaya operasional dan perawatan tetap dan variabel. Komposisi biaya produksi masingmasing skenario dapat dilihat pada Tabel 8. Dari tabel dapat dilihat bahwa biaya produksi terbesar dari masing-masing skenario adalah fixed O\&M Cost. Biaya ini meliputi biaya tenaga kerja, utilitas, dll. Secara keseluruhan, biaya produksi pellet untuk skenario 1 sebesar Rp. 870,4/kg, sedangkan untuk kompos sebesar $\mathrm{Rp}$. 475,7/kg, Biogas-cofiring mampu menggantikan cangkang untuk bahan bakar dengan biaya Rp. 537,19/kg. Biaya tertinggi adalah untuk skenario 4 sebesar $\mathrm{Rp}$. $18.061 / \mathrm{kg}$.

Dengan asumsi harga jual masingmasing produk seperti pada tabel 6 didapatkan analisa kelayakan finansial seperti NPV, IRR, BC Ratio dan payback period sebagaimana ditunjukkan pada Tabel 9. Parameter-parameter kelayakan finansial dari masing-masing skenario menunjukkan bahwa investasi untuk masing-masing teknologi adalah layak secara ekonomi, walaupun dengan waktu PBP yang lebih dari 5 tahun. Hal ini dikarenakan nilai BCR dari setiap skenario ada pada kisaran 1,36-1,97. 
Skenario 2 (PLTBg + Kompos) memiliki nilai IRR tertinggi daripada ketiga skenario lainnya. Demikian juga nilai NPV, B/C Ratio dan PBP, keempatnya menunjukkan bahwa pilihan teknologi dengan skenario 2 paling menguntungkan daripada 3 skenario yang lain. Sedangkan jika dilihat dari aspek investasi, skenario 3 masih yang paling kecil. Hal yang tidak jauh berbeda juga dari biaya produksi, skenario 2 memilki biaya produksi terendah, menyusul skenario. Biogas-cofiring dan PLTBg+Pabrik Pellet. Skenario 4 Biogas-cofiring dan Act Carbon, memiliki biaya produksi paling mahal daripada empat teknologi biorefinery lainnya.

\section{Analisa Sensitivitas}

Analisas sensitivitas dilakukan terhadap parameter finansial dengan mengubah harga jual produk dan biaya investasi. Hasil analisa sensitivitas ditunjukkan pada Tabel 9-13.
Skenario 1 masih layak sekalipun biaya investasi naik sampai 20\%. Akan tetapi menjadi tidak layak ketika harga jual pellet turun di angka 60 USD/ton. Pada harga jual pellet di angka $55 \mathrm{USD} / \mathrm{ton}$, nilai NPV menjadi negatif dan IRR di bawah dari suku bunga komersial. Saat ini listrik disuplai dari PLTBg dengan tarif sebesar Rp. 1.200/kWh. Seandainya menggunakan listrik dari PLN, investasi masih layak sampai dengan harga listrik Rp. 1.400/kWh. Pada harga listrik Rp. $1,600 / \mathrm{kWh}$, proyek menjadi tidak layak karena nilai NPV berubah negatif dan nilai IRR di bawah suku bunga komersial.

Untuk skenario 2, proyek masih layak walaupun biaya investasi naik sampai dengan $10 \%$. Namun menjadi tidak layak ketika harga jual kompos hanya di kisaran Rp. 400/kg. Pada harga kompos Rp. 400/kg, nilai NPV menjadi negatif dan IRR jauh di bawah suku bunga komersial.

Tabel 9.

Rangkuman Hasil Analisa Kelayakan Finansial dari Setiap Skenario

\begin{tabular}{lrrrr}
\hline \multicolumn{1}{c}{ Skenario } & Skenario 1 & Skenario 2 & Skenario 3 & Skenario 4 \\
\hline Parameter Finansial & & & & \\
NPV (juta Rp) & 5.031 & 7.032 & 75 & 2.490 \\
IRR (\%) & 16,08 & 18,69 & 11,38 & 17,94 \\
B/C ratio & 1,36 & 1,54 & 1,97 & 1,48 \\
PBP (thn) & 7.0 & 5,9 & 9,9 & 6,39 \\
\hline
\end{tabular}

Tabel 10.

Analisis Sensitivitas Skenario 1

\begin{tabular}{|c|c|c|c|c|}
\hline \multicolumn{5}{|c|}{ Analisis Sensitivitas Pellet Plant } \\
\hline $\begin{array}{c}\text { Harga } \\
\text { Jual } \\
\text { Pellet } \\
\text { (USD/ton) }\end{array}$ & $\begin{array}{l}\text { IRR } \\
(\%)\end{array}$ & $\begin{array}{l}\text { NPV } \\
\text { (Rp) }\end{array}$ & $\begin{array}{l}\text { Paybac } \\
\text { k Period } \\
\text { (tahun) }\end{array}$ & BCR \\
\hline 55,00 & 8,81 & -894.655 .452 & 10,00 & 0,94 \\
\hline $\begin{array}{c}60,00 \\
80,00 \\
100,00\end{array}$ & $\begin{array}{l}16,1 \\
37,9 \\
57,4\end{array}$ & $\begin{array}{c}\mathbf{5 . 0 3 1 . 7 8 2 . 4 1 8} \\
27.563 .324 .649 \\
50.094 .866 .881\end{array}$ & $\begin{array}{l}7,00 \\
3,08 \\
2,00\end{array}$ & $\begin{array}{l}1,36 \\
2,96 \\
4,57\end{array}$ \\
\hline $\begin{array}{c}\text { Biaya } \\
\text { Investasi }\end{array}$ & $\begin{array}{l}\text { IRR } \\
(\%)\end{array}$ & $\begin{array}{l}\text { NPV } \\
\text { (Rp) }\end{array}$ & $\begin{array}{c}\text { Paybac } \\
\text { k Period } \\
\text { (tahun) }\end{array}$ & BCR \\
\hline $\begin{array}{l}-20 \% \\
-10 \% \\
-5 \% \\
\text { Base } \\
+5 \% \\
+10 \% \\
+20 \% \\
\end{array}$ & $\begin{array}{l}21,3 \\
18,5 \\
17,2 \\
\mathbf{1 6 , 1} \\
15,9 \\
14,9 \\
13,1\end{array}$ & $\begin{array}{l}7.905 .433 .643 \\
6.468 .608 .031 \\
5.750 .195 .225 \\
5.031 .782 .418 \\
5.132 .573 .209 \\
4.414 .160 .402 \\
2.963 .813 .812 \\
\end{array}$ & $\begin{array}{l}5,58 \\
6,33 \\
6,67 \\
7,00 \\
7,08 \\
7,42 \\
8,08 \\
\end{array}$ & $\begin{array}{l}1,70 \\
1,51 \\
1,43 \\
1,36 \\
1,35 \\
1,29 \\
1,18 \\
\end{array}$ \\
\hline $\begin{array}{c}\text { Harga } \\
\text { Listrik } \\
\text { (Rp/kWh) }\end{array}$ & $\begin{array}{l}\text { IRR } \\
(\%)\end{array}$ & $\begin{array}{l}\text { NPV } \\
\text { (Rp) }\end{array}$ & $\begin{array}{l}\text { Paybac } \\
\text { k Period } \\
\text { (tahun) }\end{array}$ & BCR \\
\hline
\end{tabular}

\begin{tabular}{ccccc}
1.000 & 19,2 & 7.860 .930 .954 & 6,08 & 1,6 \\
$\mathbf{1 . 2 0 0}$ & $\mathbf{1 6 , 1}$ & $\mathbf{5 . 0 3 1 . 7 8 2 . 4 1 8}$ & $\mathbf{7}$ & $\mathbf{1 , 4}$ \\
1.400 & 12,8 & 2.956 .043 .327 & 8,25 & 1,2 \\
1.600 & 8,76 & -933.281 .142 & 10,08 & 0,9 \\
\hline
\end{tabular}

Tabel 11.

Analisis Sensitivitas Skenario 2

Analisis Sensitivitas Compost Plant

\begin{tabular}{|c|c|c|c|c|}
\hline $\begin{array}{c}\text { Harga } \\
\text { Jual } \\
\text { (Rp/ton) }\end{array}$ & $\begin{array}{l}\text { IRR } \\
\text { (\%) }\end{array}$ & $\begin{array}{l}\text { NPV } \\
\text { (Rp) }\end{array}$ & $\begin{array}{c}\text { Paybac } \\
\text { k Period } \\
\text { (tahun) }\end{array}$ & BCR \\
\hline 550.000 & 23,75 & 11.704 .513 .401 & 4,83 & 1,90 \\
\hline 500.000 & 18,69 & 7.032.073.767 & 5,92 & 1,54 \\
\hline 450.000 & 13,09 & 3.99 & 7,58 & 1,18 \\
\hline 400.000 & 5,78 & -2.864 .25 & 12,92 & 0,78 \\
\hline \multirow[t]{2}{*}{$\begin{array}{c}\text { Biaya } \\
\text { Investas } \\
\text { i }\end{array}$} & IRR & NPV & $\begin{array}{l}\text { Paybac } \\
\text { k Period }\end{array}$ & BCR \\
\hline & $(\%)$ & $(\mathrm{Rp})$ & (tahun) & \\
\hline$-10 \%$ & 20,51 & 067.095 & 5,50 & 1,67 \\
\hline$-5 \%$ & 19,57 & 49.584 & 5,75 & 1,60 \\
\hline Base & 18,69 & 7.032.073.767 & 5,92 & 1,54 \\
\hline$+5 \%$ & 17,86 & 6.514 .562 .693 & 6,17 & 1,49 \\
\hline$+10 \%$ & 17,06 & 5.997 .051 .618 & 6,42 & 1,43 \\
\hline
\end{tabular}


Untuk skenario 3, proyek menjadi tidak layak ketika biaya investasi naik sampai dengan 10\%. Demikian juga apabila nilai jual cangkang di bawah Rp. 500/kg. Pada harga cangkang Rp. 450/kg, nilai NPV dan IRR menjadi negatif.

Untuk skenario 4, harga jual minimal untuk activated carbon adalah Rp. 20.000 per $\mathrm{kg}$. Dibawah itu proyek menjadi tidak layak. Sedangkan biaya investasi masih relatif tidak berpengaruh terhadap kelayakan proyek, sampai dengan penambahan biaya investasi sebesar $10 \%$.

Tabel 12

Analisis Sensitivitas Skenario 3
Tabel 13.

Analisis Sensitivitas Skenario 4

Analisis Sensitivitas Biogas Cofiring + Active Carbon

\begin{tabular}{|c|c|c|c|c|}
\hline $\begin{array}{c}\text { Harga } \\
\text { Jual Act } \\
\text { Carbon } \\
\text { (Rp/kg) }\end{array}$ & $\begin{array}{l}\text { IRR } \\
\text { (\%) }\end{array}$ & NPV & $\begin{array}{c}\text { Payback } \\
\text { Period } \\
\text { (tahun) }\end{array}$ & $B C R$ \\
\hline 30.000 & 36,25 & 9.522 .064 .717 & 3,24 & 2,84 \\
\hline 25.000 & 27,49 & 6.005 .945 .231 & 4,32 & 2,16 \\
\hline 20.000 & 17,70 & 2.687 .499 .324 & 6,46 & 1,47 \\
\hline 15.000 & 5,22 & -1.266 .570 .082 & 12,89 & 0,75 \\
\hline 10.000 & & -5.748 .174 .338 & 0,00 & $-0,11$ \\
\hline \multirow[t]{2}{*}{$\begin{array}{c}\text { Biaya } \\
\text { Investasi }\end{array}$} & IRR & NPV & \multirow{2}{*}{$\begin{array}{l}\text { Payback } \\
\text { Period } \\
\text { (tahun) }\end{array}$} & \multirow[t]{2}{*}{ BCR } \\
\hline & (\%) & (Rp) & & \\
\hline$-10 \%$ & 20,15 & 3.264 .181 .103 & 5,79 & 1,63 \\
\hline$-5 \%$ & 18,87 & 2.975 .840 .213 & 6,13 & 1,55 \\
\hline Base & 17,70 & 2.687.499.324 & 6,46 & 1,47 \\
\hline & 10 & 158 & 6,8 & 1,40 \\
\hline$+10 \%$ & 15,61 & 2.110 .817 .546 & 7,13 & 1,33 \\
\hline
\end{tabular}

\section{SIMPULAN}

Hasil kajian menunjukkan bahwa teknologi biorefinery baik itu skenario 1 , skenario 2, skenario 3 maupun skenario 4 , layak untuk diterapkan di PKS. Saat ini PKS sudah memiliki PLTBg, sehingga teknologi pellet maupun kompos dapat diterapkan dan memiliki kelayakan finansial yang cukup menarik. Dengan dipasangnya teknologi pellet maupun kompos, diharapkan dapat mengurangi limbah tandan kosong, yang

Dari hasil di atas, untuk kasus PKS, dimana sudah terpasang PLTBg, direkomendasikan untuk menambah fasilitas pengolahan tankos menjadi kompos, yang mana memiliki parameter keekonomian yang paling menguntungkan. Sedangkan untuk PKS di tempat lain, yang mana belum terpasang PLTBg, opsi pemanfaatan biogas untuk bahan bakar pengganti cangkang, perlu dipertimbangkan karena cangkang yang dihemat memiliki nilai ekonomi yang cukup menguntungkan, apalagi apabila cangkang tersebut diolah lebih lanjut menjadi Karbon Aktif yang memiliki nilai tambah jauh lebih tinggi daripada dijual sebagai cangkang begitu saja. 


\section{UCAPAN TERIMA KASIH}

Terima kasih diucapkan kepada pihak Kementerian Riset dan Teknologi, atas dukungan pembiayaan melalui insentif sistem inovasi nasional TA. 2019, dan PT. Perkebunan Nusantara V, yang memfasilitasi dan bersedia menjadi objek studi dari kegiatan ini.

\section{DAFTAR PUSTAKA}

1. Gabungan Pengusaha Kelapa Sawit Indonesia (GAPKI), Kinerja Industri Sawit Indonesia 2019, Februari 2020.

2. Hilmawan, E., Renewable Energy from Bioresources in Indonesia Technology and Challenges, dipresentasikan pada Grand Seminar - Indonesia Chemical Engineering Challenge (IChEC), Institut Teknologi Bandung, 25 Februari 2017.

3. Jong E., Higson, A., Walsh, and Welisch, M., Bio-Base Chemicals Value Added Products from Biorefineries, IEA Bioenergy, Task 42 Biorefinery Report, Januari 2012.

4. Cherubini, F., Jungmeier, G., et.al., Toward a Common Classification approach for Biorefinery Systems, Biofuels, Bioprod. Bioref., 2009, DOI: 10.1002/bbb.

5. Ahmad, F.B., et.al., The outlook of the Production of advanced fuels and chemicals from integrated oil palm biomass biorefinery, Ren. Sust. Energy Rev., Vol. 109, 2019, pp386-411,

6. Garcia-Nunez, J.A., RamirezContreras, N.E., et. al., Evolution of Palm Oil Mills into bio-refineries: Literature review on current and potential uses of residual biomass and effluents, Resource, Conservation and Recycling, Vol. 110, 2016, pp99-114.

7. Chang, S.H., An overview of empty fruit bunch from oil palm as feedstock for bio-oil production, Biomass and Bioenergy, Vol. 62, 2014, pp174-181.

8. European Association of Research and Technology Organisations, The TRL Scale as a Research \& Innovation Policy Tool, EARTO Recommendations, Brussels, 2014, pp1-17.

9. U.S. Department of Defence, Technology Readiness Assessment (TRA)-Guidance, Washington, 2011.

10. Héder, M., From NASA to EU: the evolution of the TRL scale in Public Sector Innovation, The Innovation
Journal: The Public Sector Innovation Journal, Vol. 22 (2), 2017.

11. Garcia-Nunez, J.A., Rodriguez, D.T., et.al., Evaluation of alternatives for the evolution of palm oil mills into biorefineries, Biomass and Bioenergy, Vol. 95, 2016, pp310-329.

12. Yoshizaki, T., Shirai, Y., Hassan, M.A., et. al., Improved economic viability of integrated biogas energyand compost production for sustainable palm oil mill management, J. Clean.Prod., Vol. 44, 2013.

13. Prasertsan, S., and Sajjakulnukit, B., Biomass and biogas energy in Thailand: Potential, opportunity and barriers, Renewable Energy, Vol. 31 (5), 2006, pp599-610.

14. Suhaimi, M., and Ong, H.K., Composting Empty Fruit Bunches of Oil Palm, Malaysian Agricultural Research and Development Institute, 2001.

15. Darnoko, D., Guritno, P., and Schuchardt, F., Simultaneous Utilization of Fresh Pome and EFB for Compost

16. Production, Porim International Palm Oi Conference, Kuala Lumpur, 2003.

17. Schuchardt, F., Darnoko, D., and Guritno, P., Composting of Empty Oil Palm Fruit Bunch (EFB) with Simultaneous Evaparation of Oil Mill Waste Water (POME), International Oil Palm Conference - Nusa Dua, Bali, 2002.

18. Jeong, J.Y., et.al., Production of bio-oil rich in acetic acid and phenol from fast pyrolysis of palm residues using a fluidized bed reactor: Influence of activated carbons, Bioresource Technology, Vol. 219, November 2016, pp357-364.

19. Chiew, Y.L. and Shimada, S., Current state and environmental impact assessment for utilizing oil palm empty fruit bunches for fuel, fiber and fertilizer - A case study of Malaysia, Biomass and Bioenergy, Vol. 51, 2013, pp109124.

20. Jamal, P., Idris, Z.M., et.al., Effects of physicochemical parameters on the production of phenolic acids from palm oil mill effluent under liquid-state fermentation by Aspergillus niger IBS103ZA, Food Chemistry, Vol. 124, Issue 4, 2011, pp1595-1602.

21. Takkellapati, S., Li, T., and Gonzalez, M.A., An Overview of Biorefinery Derived Platform Chemicals from a Cellulose and Hemicellulose 
Biorefinery, Clean Technology Environment Policy, Vol. 20 (7), 2018, pp1615-1630.

22. Hassan, M. A., et.al., Sustainable production of polyhydroxyalkanoates from renewable oil-palm biomass, Biomass and Bioenergy, Vol. 50, March 2013, pp1-9.

23. Zahari, M.A.K.M., et. al., Case study for a palm biomass biorefinery utilizing renewable non-food sugars from oil palm frond for the production of poly(3hydroxybutyrate) bioplastic, Journal of Cleaner Production, Vol. 87, 2015, pp 284-290.

24. Hossain, M.A., Jewaratnam, J., Ganesan, P., Prospect of hydrogen production from oil palm biomass by thermochemical process - a review, Int. Journal of Hydrogen Energy, Vol. 41 (38), 2016, pp16637-166

25. 55

26. Zailuddin, N.L.I., and Husseinsyah, S., Tensile Properties and Morphology of Oil Palm Empty Fruit Bunch Regenerated Cellulose Biocomposite Films, Procedia Chemistry, Vol. 19, 2016, pp366-372.

27. Shinoj, S., Visvanathan, R., et.al., Oil palm fiber (OPF) and its composites: $A$ review, Industrial Crops and Products, Vol. 33 (1), 2011, pp7-22.
28. Boateng, C.O., and Lee, K.T., An oil palm-based biorefinery concept for cellulosic ethanol and phytochemicals production: Sustainability evaluation using exergetic life cycle assessment, Applied Thermal Engineering, Vol. 62, 2014, pp90-104.

29. Vaskan, P., Pachón, E.R., and Gnansounou, E., Techno-economic and life-cycle assessments of biorefineries based on palm empty fruit bunches in Brazil, Journal of Cleaner Production, Vol. 172, 2018, pp3655-3668.

30. Choi, G.G., Oh, S.J., et.al., Production of bio-based phenolic resin and activated carbon from bio-oil and biochar derived from fast pyrolysis of palm kernel shells, Bioresource Technology, Vol. 178, 2015, pp99-107.

31. Chin, M.J., Poh, P.E., Tey, B.T., et.al., Biogas from Palm Oil Mill Effluent (POME): Opportunitis and challenges from Malaysia's perpective, Ren. Sust. Energy Rev., Vol. 26, 2013, pp717-726.

32. Aziz, M.A., et.al., Recent advances on palm oil mill effluent (POME) pretreatment and anaerobic reactor for sustainable biogas production, Renewable and Sustainable Energy Reviews, Vol. 119, Article No. 109603, 2020. 